\title{
Cutaneous leishmaniasis: immune responses in protection and pathogenesis
}

\section{Phillip Scott and Fernanda O. Novais}

\begin{abstract}
Cutaneous leishmaniasis is a major public health problem and causes a range of diseases from self-healing infections to chronic disfiguring disease. Currently, there is no vaccine for leishmaniasis, and drug therapy is often ineffective. Since the discovery of CD4 ${ }^{+} T$ helper 1 $\left(T_{H} 1\right)$ cells and $T_{H} 2$ cells 30 years ago, studies of cutaneous leishmaniasis in mice have answered basic immunological questions concerning the development and maintenance of $\mathrm{CD} 4^{+} \mathrm{T}$ cell subsets. However, new strategies for controlling the human disease have not been forthcoming. Nevertheless, advances in our knowledge of the cells that participate in protection against Leishmania infection and the cells that mediate increased pathology have highlighted new approaches for vaccine development and immunotherapy. In this Review, we discuss the early events associated with infection, the $\mathrm{CD} 4^{+} T$ cells that mediate protective immunity and the pathological role that $\mathrm{CD} 8^{+} \mathrm{T}$ cells can have in cutaneous leishmaniasis.
\end{abstract}

Delayed-type hypersensitivity (DTH). An inflammatory response that develops 48-72 $\mathrm{h}$ after injection of antigen into the skin. DTH indicates that an individual has a population of $T$ cells that make interferon- $\gamma$ and recognize that antigen
Department of Pathobiology, School of Veterinary Medicine, University of Pennsylvania, 380 South University Avenue, Philadelphia, Pennsylvania 19104-4539, USA.

Correspondence to P.S. pscott@vet.upenn.edu
Cutaneous leishmaniasis - which is caused by several protozoal parasites of the genus Leishmania - is endemic to South and Central America, Northern Africa, the Middle East and parts of Asia, and an estimated 1 million new cases arise each year ${ }^{1}$. Of particular interest to immunologists is the wide range of clinical manifestations associated with this disease, which, similar to tuberculosis and leprosy, is dictated largely by the type and magnitude of the immune response of the host. As in most infections, the immune response to cutaneous leishmaniasis depends on many host factors, as well as on the differences between the infecting Leishmania spp. Experimental infections in mice also exhibit a spectrum of clinical presentations depending on the mouse strain and the infecting parasite species or strain used (TABLE 1).

The immunological spectrum observed in patients with leishmaniasis ranges from individuals with a strong $\mathrm{T}$ cell response, characterized by delayed-type hypersensitivity (DTH) and high levels of interferon- $\gamma$ (IFN $\gamma$ ), to individuals who lack a DTH response but may have high levels of antibodies ${ }^{2}$. Because Leishmania spp. are killed by IFN $\gamma$-activated macrophages and are not neutralized by antibodies, individuals with a strong DTH have few parasites in their lesions, whereas those with only a humoral response are unable to control the parasite load ${ }^{2,3}$. As expected, patients without a $\mathrm{T}$ cell response exhibit a severe disease called diffuse cutaneous leishmaniasis. At the other end of the spectrum, patients with an exaggerated immune response also develop a severe disease phenotype known as mucosal leishmaniasis, which is driven by immunopathology. Between these extremes are patients who develop lesions that may self-heal or become chronic, with intermediate levels of T cell and antibody responses ${ }^{4}$ (FIG. 1).

The differential development of $\mathrm{T}$ helper $1\left(\mathrm{~T}_{\mathrm{H}} 1\right)$ and $\mathrm{T}_{\mathrm{H}}$ 2-type responses was initially thought to translate directly to the spectrum of clinical presentations seen in patients. This reasoning was based on findings that $\mathrm{CD}^{+} \mathrm{T}_{\mathrm{H}} 1$ cells mediate resistance in Leishmania major-infected mice whereas $\mathrm{CD}^{+} \mathrm{T}_{\mathrm{H}} 2$ cells promote susceptibility ${ }^{5,6}$. However, advances in our understanding of the disease in both humans and mice indicate that a more complex cellular response dictates the outcome of infection. In particular, substantial advances have been made in our understanding of both protective and pathological immune responses to leishmanial infection. These advances should ultimately influence the development of vaccines and immunotherapies for leishmaniasis. In this Review, we discuss these advances and, where possible, link findings in mouse models to human disease.

\section{Early immune responses to Leishmania}

Several Leishmania spp. cause cutaneous leishmaniasis, and each species has individual characteristics. However, they share a similar life cycle in which a sand fly transmits a flagellated form of the parasite, called a promastigote, to mammalian hosts, including humans, 
dogs and rodents ${ }^{7}$. Once the promastigotes are injected into the skin via the bite of a sand fly, they enter several types of phagocytic cells. Within the phagolysosome of macrophages, promastigotes transform to a round non-flagellated replicative form called an amastigote. The life cycle is complete when sand flies ingest amastigotes while feeding on a host, and the amastigotes subsequently transform to promastigotes and replicate within the sand fly. Most experimental infections involve injecting promastigotes into the skin with a needle; however, during a natural infection, additional factors present in the sand fly saliva are introduced in the skin that influence early immune responses ${ }^{8}$. Hence, the biological significance of studies investigating the early response to infection without considering the conditions present during natural infection, such as the inoculation site, number of parasites and the components present during the sand fly bite, should be carefully interpreted ${ }^{9,10}$.

Although macrophages are the primary host cell for Leishmania parasites, monocytes, dendritic cells (DCs) and neutrophils that are recruited to the infection site can become infected and have important and distinct roles in shaping the immune response to infection.

The role of neutrophils. Neutrophils are rapidly recruited to the site of a Leishmania infection ${ }^{11}$, but their role here is complicated; they may kill the parasites or protect them depending on the parasite species and the host. For example, Leishmania amazonensis promastigotes are killed by neutrophil extracellular traps (NETs) ${ }^{12,13}$ (FIG. 2a); however, salivary proteins from the sand fly can protect the parasites against neutrophil-mediated death $^{14}$. Thus, it remains unclear whether NETs have a protective role in vivo. Neutrophils can also contribute to the control of Leishmania braziliensis and L. amazonensis by interacting with infected macrophages ${ }^{15,16}$ (FIG. 2a). By contrast, uptake of apoptotic neutrophils by macrophages and DCs after L. major infection can limit the activation of macrophages and DCs, leading to better parasite survival ${ }^{17,18}$. However, this process may not occur with every Leishmania spp. because apoptosis was not observed following Leishmania mexicana infections ${ }^{19}$. Neutrophils also promote increased CC-chemokine ligand 3 (CCL3)-dependent recruitment of $\mathrm{DCs}^{20}$, and the expression of apoptotic markers on neutrophils promotes their preferential phagocytosis by $\mathrm{DCs}^{21}$. The consequent decrease in DC activation reduces the ensuing $\mathrm{T}_{\mathrm{H}} 1$-type response and inhibits cross-presentation for $\mathrm{CD}^{+} \mathrm{T}$ cell activation ${ }^{21,22}$ (FIG. 2b).

Studies of Leishmania infection in the absence of neutrophils suggest that the role of neutrophils depends on the genetic background of the host. For example, neutrophil-depleted C57BL/6 mice exhibit a normal course of infection with L. major, whereas neutrophil depletion in BALB/c mice blocks the early characteristic interleukin-4 (IL-4) response and thereby inhibits the development of the non-protective $\mathrm{T}_{\mathrm{H}} 2$-type response $\mathrm{e}^{23}$. However, evaluating the in vivo role of neutrophils is complicated because the monoclonal antibody (mAb) that is most frequently used to deplete neutrophils, RB6-8C5, recognizes both LY6G (which is expressed on neutrophils) and LY6C (which is expressed on other cells, including monocytes). Studies using the more specific mAb $1 \mathrm{~A} 8$ and the use of neutropaenic Genista mice ${ }^{24}$ will need to be performed to help resolve this issue. Strikingly, Genista mice are resistant to infection with parasites that normally cause non-healing lesions, such as L. mexicana and the Seidman strain of L. major ${ }^{19,25}$, which suggests that neutrophils may have

\begin{tabular}{|c|c|c|c|c|c|c|}
\hline \multirow[t]{3}{*}{ Leishmania spp. } & \multirow[t]{3}{*}{ Human disease } & \multicolumn{4}{|c|}{ Mouse disease } & \multirow[t]{3}{*}{ Refs } \\
\hline & & \multicolumn{2}{|c|}{ C57BL/6 mice } & \multicolumn{2}{|l|}{ BALB/c mice } & \\
\hline & & $\begin{array}{l}\text { Type of } \\
\text { disease }\end{array}$ & $\begin{array}{l}\text { Dominant } \\
\text { immune } \\
\text { response }\end{array}$ & $\begin{array}{l}\text { Type of } \\
\text { disease }\end{array}$ & $\begin{array}{l}\text { Dominant } \\
\text { immune } \\
\text { response }\end{array}$ & \\
\hline Leishmania major & $\begin{array}{l}\text { Self-healing or chronic cutaneous } \\
\text { leishmaniasis usually caused by a } \\
\text { single skin lesion }\end{array}$ & Self-healing & $\mathrm{T}_{\mathrm{H}} 1$ & Chronic & $\mathrm{T}_{\mathrm{H}} 2$ & 5,6 \\
\hline $\begin{array}{l}\text { Leishmania major } \\
\text { Seidman strain }\end{array}$ & Chronic cutaneous leishmaniasis & Chronic & $\mathrm{T}_{\mathrm{H}} 1$ & Chronic & $\mathrm{T}_{\mathrm{H}} 2$ & 138 \\
\hline $\begin{array}{l}\text { Leishmania } \\
\text { amazonensis }\end{array}$ & $\begin{array}{l}\text { Self-healing or chronic cutaneous } \\
\text { leishmaniasis usually caused by } \\
\text { a single skin lesion, and diffuse } \\
\text { cutaneous leishmaniasis }\end{array}$ & Chronic & $\begin{array}{l}\mathrm{T}_{\mathrm{H}} 1 \text { and } \\
\mathrm{T}_{\mathrm{H}} 2\end{array}$ & Chronic & $\mathrm{T}_{\mathrm{H}} 2$ & 139-141 \\
\hline $\begin{array}{l}\text { Leishmania } \\
\text { mexicana }\end{array}$ & $\begin{array}{l}\text { Healing or chronic cutaneous } \\
\text { leishmaniasis usually caused by } \\
\text { a single skin lesion, and diffuse } \\
\text { cutaneous leishmaniasis }\end{array}$ & Chronic & $\begin{array}{l}\mathrm{T}_{\mathrm{H}} 1 \text { and } \\
\mathrm{T}_{\mathrm{H}} 2\end{array}$ & Chronic & $\mathrm{T}_{\mathrm{H}} 2$ & $\begin{array}{r}139,142 \\
143\end{array}$ \\
\hline $\begin{array}{l}\text { Leishmania } \\
\text { braziliensis }\end{array}$ & $\begin{array}{l}\text { Healing or chronic cutaneous } \\
\text { leishmaniasis usually caused by } \\
\text { a single skin lesion, and mucosal } \\
\text { leishmaniasis }\end{array}$ & Self-healing & $\mathrm{T}_{\mathrm{H}} 1$ & Self-healing & $\mathrm{T}_{\mathrm{H}} 1$ & 76 \\
\hline
\end{tabular}


Respiratory burst The rapid release of reactive oxygen species from immune cells during phagocytosis.

CC-chemokine receptor 2 (CCR2). A receptor that binds monocyte chemoattractant protein (CCL2) and is involved in monocyte migration from the bone marrow to inflammatory sites.

Reactive oxygen species (ROS). Chemically reactive molecules that contain oxygen, and include superoxide anions, hydroxyl radicals and hydrogen peroxide.

Nitric oxide

(NO). A free radical that is a gas that performs several biological functions and is involved in killing pathogens by macrophages. a primarily detrimental role. However, further studies using different parasite species in different genetic backgrounds will be required to obtain a clear picture of their in vivo role in cutaneous leishmaniasis.

The role of DCs and inflammatory monocytes. Inflammatory monocytes and DCs are also recruited to the site of infection, and over the first few days become the dominant cells infected with Leishmania parasites $^{21}$ (FIG. 2C). Even within the first few hours of infection, some DCs and monocytes are infected with the parasites ${ }^{26,27}$. The early recruitment of inflammatory monocytes is dependent on CCL2, which is produced by cells within the infection site following activation by platelet-derived growth factor ${ }^{27}$. The consequence of monocyte infection is markedly different from infection of macrophages; monocytes exhibit a strong respiratory burst upon infection, leading to early parasite control, whereas macrophages need to be activated by IFN $\gamma$ to kill the parasites ${ }^{27}$ (FIG. 2C). C57BL/6 mice lacking CC-chemokine receptor 2 (CCR2) develop a non-healing $L$. major infection, which is characterized by an increased and sustained recruitment of neutrophils and the development of a CD4 $4^{+} \mathrm{T}_{\mathrm{H}} 2$-type response ${ }^{28}$. Furthermore, in neutropaenic Genista mice, increased resistance to infection correlated with the recruitment of inflammatory monocytes ${ }^{19}$. Taken together, current data suggest a protective role for monocytes in Leishmania infection, although more in vivo studies are needed to confirm this role. Thus, although neutrophils may have a dual role during infection, inflammatory monocytes seem to be important in controlling the infection.

Innate mechanisms of Leishmania killing. The two major mechanisms responsible for controlling Leishmania parasites are the production of reactive oxygen species (ROS), generated by the respiratory burst that occurs during phagocytosis, and nitric oxide (NO), generated by inducible NO synthase (iNOS) following activa-

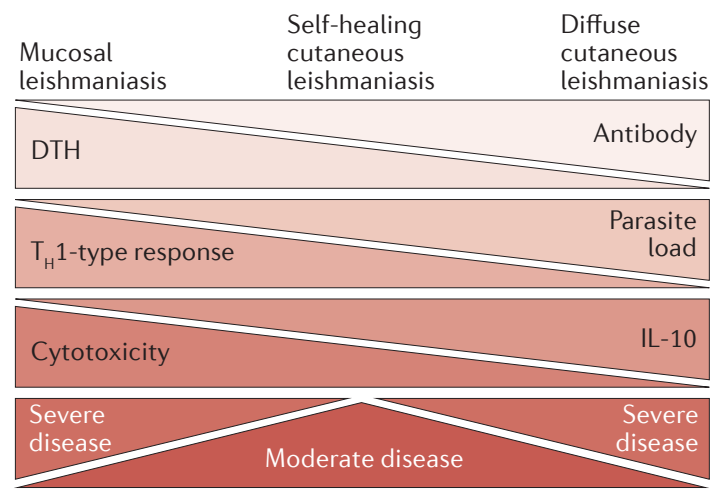

Figure 1 | Spectrum of disease in human cutaneous and mucosal leishmaniasis. Mucosal and diffuse cutaneous leishmaniasis are severe forms of disease that fall on opposite ends of the immunological spectrum. The spectrum ranges from high levels of cell-mediated immunity to high levels of antibody. Although all clinical forms require Thelper $1\left(T_{H} 1\right)$-type responses to cure the disease, an exacerbated $\mathrm{T}_{\mathrm{H}} 1$-type response and an increased number of $\mathrm{CD} 8^{+}$cytotoxic $\mathrm{T}$ cells are associated with increased disease severity. The consequence of an extremely exaggerated cellular response is the development of mucosal leishmaniasis, in which parasites metastasize to the nasopharyngeal mucosa and cause disfiguring lesions. By contrast, patients at the other end of the spectrum have high parasite numbers within the lesions, which is a consequence of low levels of $\mathrm{T}_{\mathrm{H}} 1$ cytokines. This form of the disease, termed diffuse cutaneous leishmaniasis, is also associated with high antibody titres. In addition, patients with diffuse cutaneous leishmaniasis produce high levels of the regulatory cytokine interleukin-10 (IL-10), whereas patients with mucosal leishmaniasis have low levels of IL-10. DTH, delayed-type hypersensitivity.

within the NO-producing cell and those in bystander cells $^{35}$. In mice, NO is considered essential for controlling Leishmania, as iNOS-deficient mice are susceptible to L. major infection even though they develop a greater $\mathrm{T}_{\mathrm{H}} 1$-type response compared with wild-type mice $^{36}$. However, the role of NO in humans is less clear. Although in vitro blockade of NO can affect parasite growth in human macrophages in some studies, NO cannot be measured in human cell cultures ${ }^{37}$. Although iNOS expression has been detected in lesions from patients with cutaneous leishmaniasis ${ }^{38}$, there was no change in the expression of the human gene encoding iNOS (NOS2) in lesions of patients with cutaneous leishmaniasis compared with normal skin ${ }^{31}$. Thus, although $\mathrm{NO}$ is the main mediator of killing Leishmania in mice, the relative roles of ROS and NO for Leishmania control in humans remain unclear. Leishmania s deficient in components of the NADPH complex, which is required to generate ROS, can still control disease ${ }^{32}$. This effect is probably due to the important role of NO in mouse models of Leishmania infection.

IFN $\gamma$ and tumour necrosis factor (TNF) act synergistically to promote optimal activation of macrophages to eliminate Leishmania parasites by inducing iNOS $^{33,34}$. As NO can diffuse across cell membranes, it can mediate killing of both intracellular parasites

\section{Adaptive immunity to Leishmania}

Early adaptive immune responses. The early immune response is important in determining whether a Leishmania infection in the skin will be self-healing or chronic. Experimental L. major infections in varitors promoting the differential development of $\mathrm{T}_{\mathrm{H}} 1$ and $\mathrm{T}_{\mathrm{H}} 2$ cells. Some mouse strains develop $\mathrm{CD} 4^{+}$ ous mouse strains have been used to identify the fac- 
IL-12

A heterodimeric cytokine containing an IL-12p35 and an IL-1 2 p40 chain that stimulates the production of interferon- $\gamma$ from cells. IL-12 is crucial for the differentiation of $\mathrm{CD}_{4}^{+}$ Thelper 1 cells
$\mathrm{T}_{\mathrm{H}} 1$ cell-mediated resistance following infection with L. major, whereas other mouse strains develop a $\mathrm{CD} 4^{+}$ $\mathrm{T}_{\mathrm{H}} 2$-type response and are extremely susceptible to infection (TABLE 1). IL-1 2 is essential for the development of protective $\mathrm{CD} 4^{+} \mathrm{T}_{\mathrm{H}} 1$ cells, as determined by a combination of antibody treatments and knockout mice ${ }^{39,40}$. By contrast, IL- 4 promotes $\mathrm{T}_{\mathrm{H}} 2$ cell development and susceptibility in mice $^{41}$, but the degree to which CD $4^{+}$ $\mathrm{T}_{\mathrm{H}} 2$ cells mediate susceptibility in human leishmaniasis is less clear.
DCs initiate the antigen-specific immune response to Leishmania and are the main source of IL-12 (REF. 42). Some DCs that prime naive $\mathrm{T}$ cells are resident in the lymph node ${ }^{43}$, but most DCs are derived from inflammatory monocytes that are recruited to the cutaneous lesion and subsequently differentiate into monocyte-derived DCs that migrate to the draining lymph node (DLN) ${ }^{44}$ (FIG. 2c). Before the development of $\mathrm{T}_{\mathrm{H}} 1$ cells, IFN $\gamma$ is primarily produced by natural killer (NK) cells within the $\mathrm{DLN}^{45}$, which reside in close association with DCs. Once a

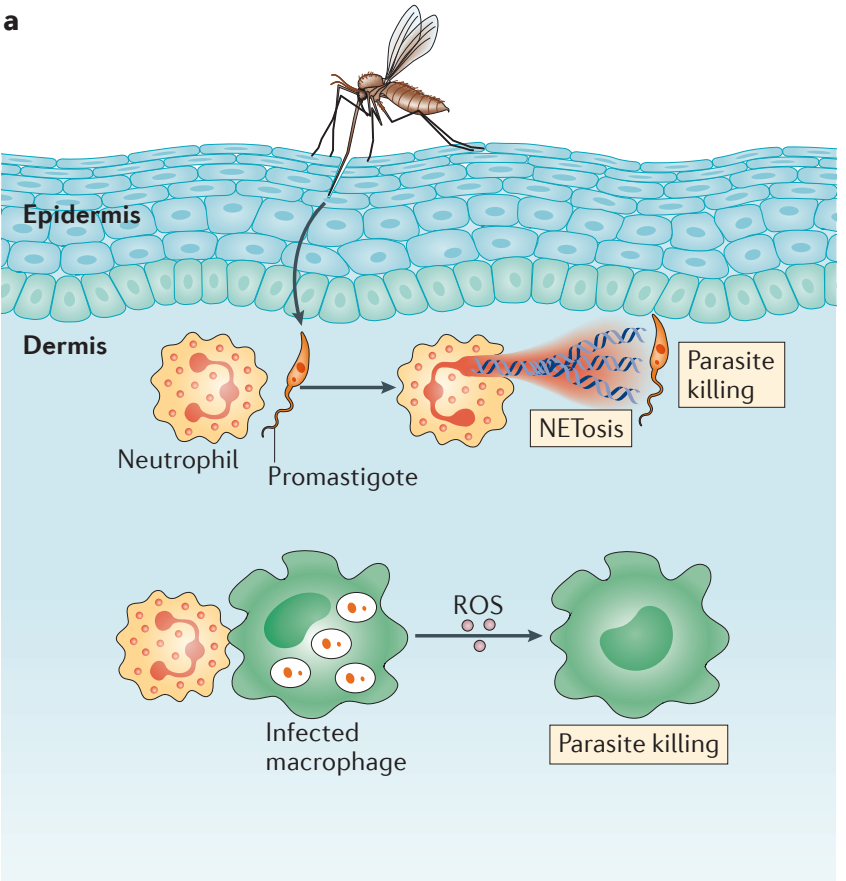

b

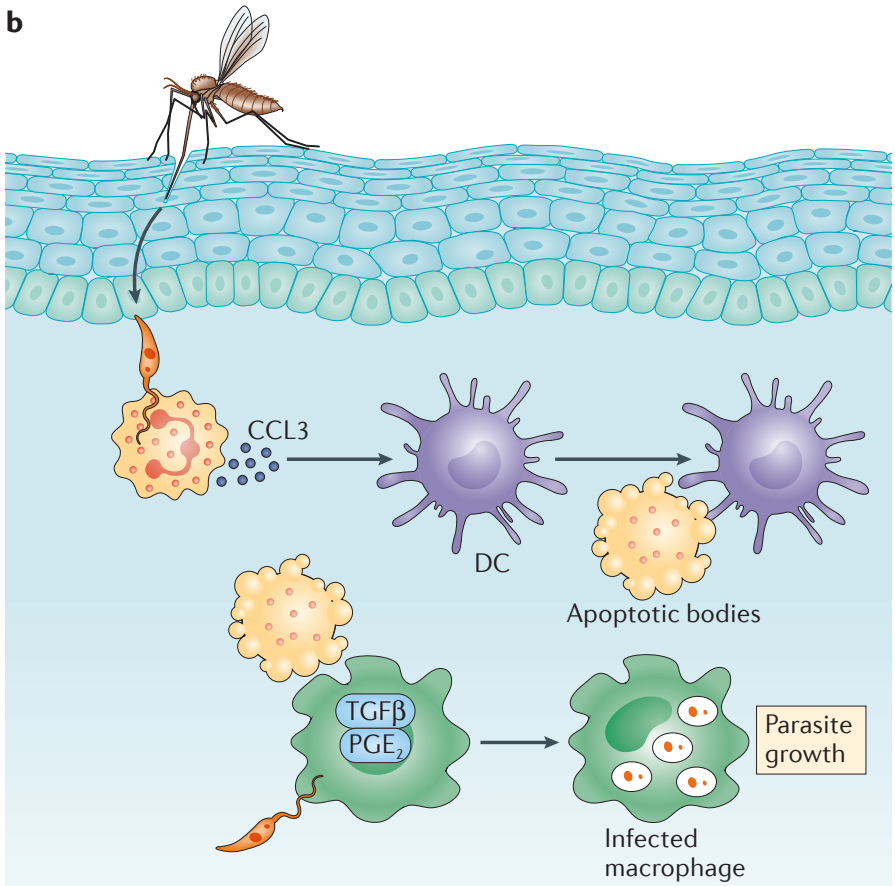

C

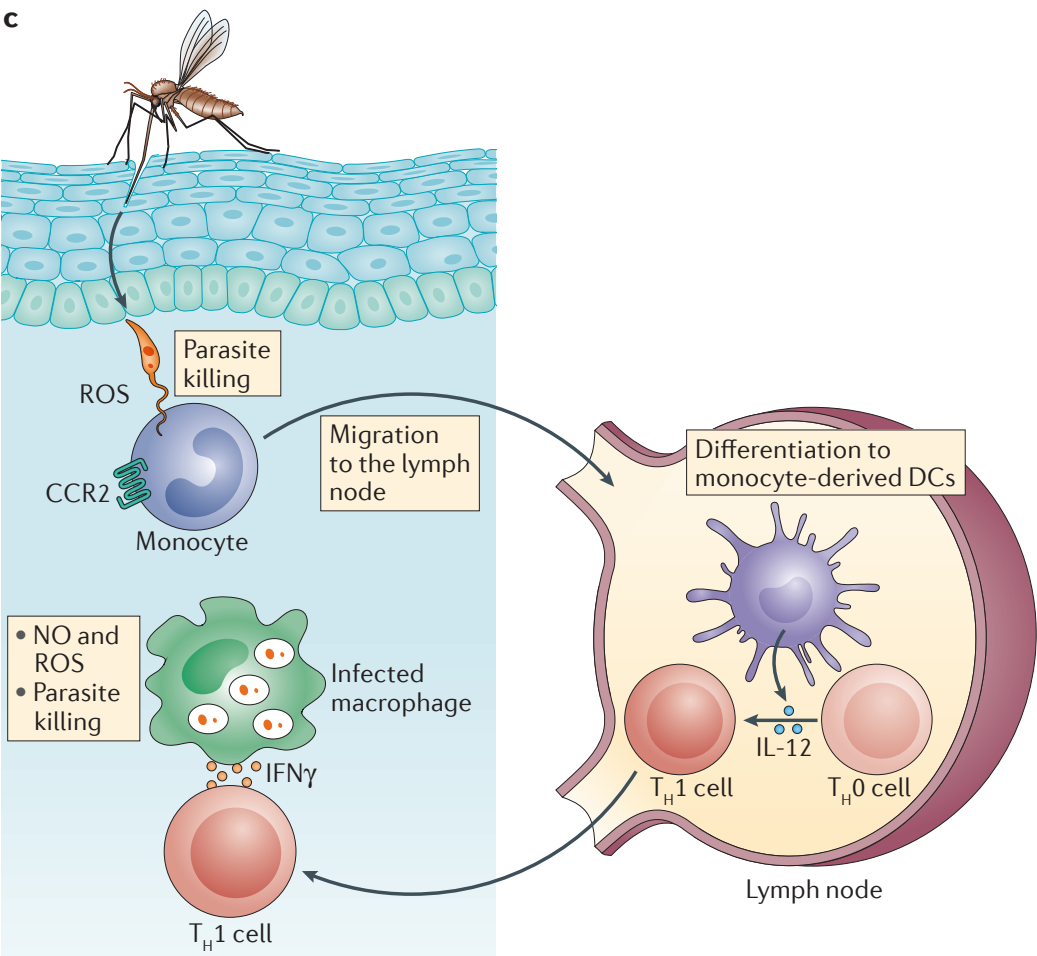

Figure 2 | The involvement of innate cells in parasite persistence and control of infection. a Early after infection with Leishmania parasites, neutrophils can release neutrophil extracellular traps (NETs) and kill Leishmania promastigotes (NETosis). Live or necrotic neutrophils can also activate infected macrophages and induce parasite control in a reactive oxygen species (ROS)-dependent manner. $\mathbf{b} \mid$ Neutrophils are present early after infection with Leishmania and recruit dendritic cells (DCs) to the site of infection by producing CC-chemokine ligand 3 (CCL3). After dying by apoptosis in the skin, neutrophils suppress the activation of DCs and macrophages, which results in parasite growth and inefficient activation of T helper $1\left(\mathrm{~T}_{H} 1\right)$ cells and $C D 8^{+}$ T cells. c | Monocytes are also recruited from the blood to the Leishmania lesions in a CC-chemokine receptor 2 (CCR2)-dependent manner; in contrast to neutrophils, monocytes are efficient at killing Leishmania parasites by producing ROS. Monocytes also differentiate into DCs, migrate to the lymph nodes and promote the differentiation of $\mathrm{T}_{\mathrm{H}} 1$ cells by producing interleukin-12 (IL-12). $T_{H} 1$ cells then migrate to the skin and eliminate the parasites by inducing nitric oxide (NO) production and/or enhancing the respiratory burst. IFN $\gamma$, interferon- $\gamma ; \mathrm{PGE}_{2}$, prostaglandin $\mathrm{E}_{2} ; \mathrm{TGF} \beta$, transforming growth factor- $\beta$. 
a Lymph node

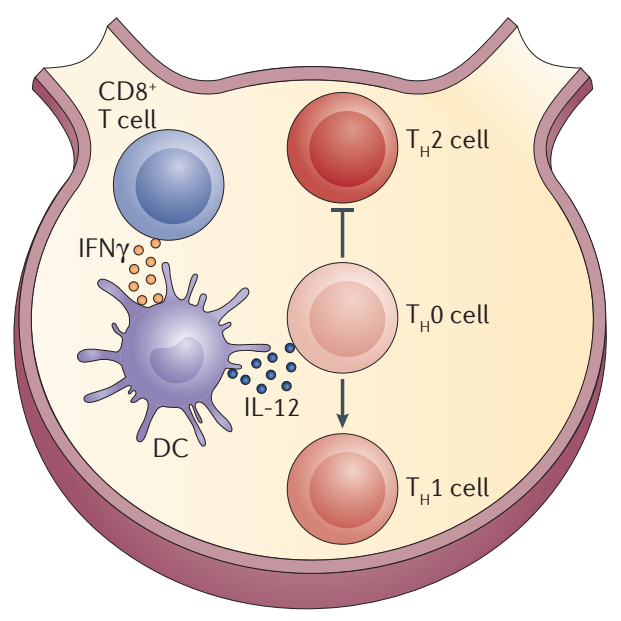

b Skin

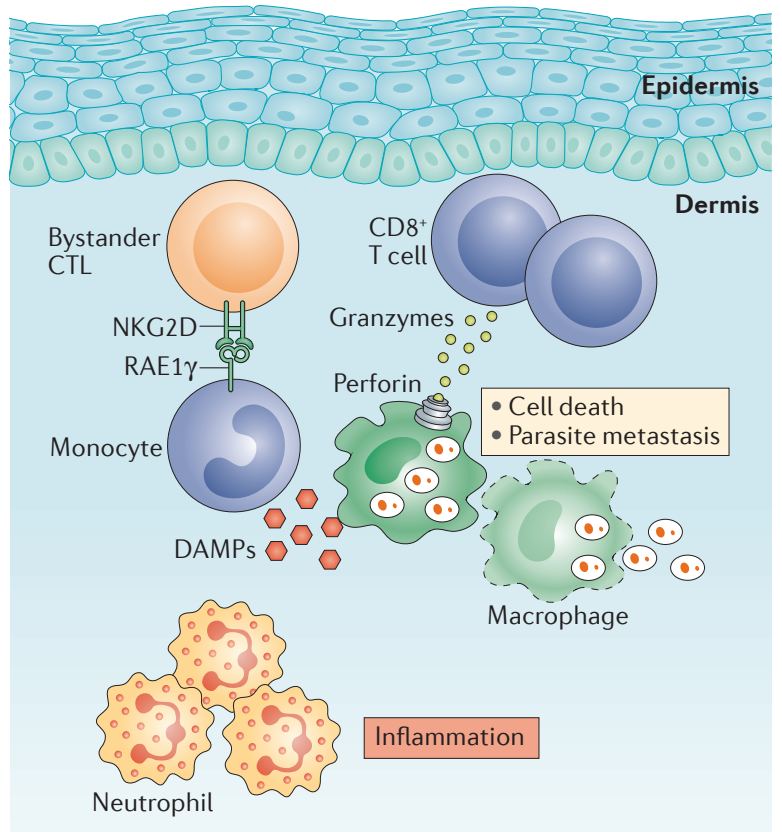

Figure $3 \mid$ The dual role of $\mathrm{CD}^{+} \mathbf{T}$ cells in leishmaniasis. a | During the priming of Thelper $1\left(\mathrm{~T}_{\mathrm{H}} 1\right) \mathrm{cells}, \mathrm{CD} 8^{+} \mathrm{T}$ cells produce interferon- $\gamma$ (IFN $\gamma$ ) in the lymph nodes and activate dendritic cells (DCs) to produce the interleukin-12 (IL-12) necessary for $\mathrm{T}_{\mathrm{H}} 1$ cell differentiation and $\mathrm{T}_{\mathrm{H}} 2$ cell suppression. Not depicted are natural killer cells that can also provide the initial IFN $\gamma$ production necessary for $\mathrm{T}_{H} 1$ cell differentiation. $\mathbf{b} \mid \ln$ the skin, parasite-specific and bystander cytotoxic T lymphocytes (CTLs) are present. Bystander CD8 ${ }^{+}$T cells recognize signals — retinoic acid early transcript $1 \gamma(\mathrm{RAE} 1 \gamma)$ in the mouse and MHC class I polypeptide-related sequence A (MICA) and MICB in humans - that are present on the surface of innate cells such as monocytes. $C D 8^{+} T$ cells induce target cell death in an natural killer group 2, member D (NKG2D)-dependent manner. CD8 ${ }^{+} \mathrm{T}$ cells that recognize Leishmania antigen promote granule-mediated cytotoxicity in the skin and induce target cell death. Dead cells release parasites and damage-associated molecular patterns (DAMPS), which leads to spread of the parasite and severe inflammation.

activated by $L$. major infection, NK cells are recruited to the paracortex where they produce IFN $\gamma^{46}$, which enhances the production of IL-12 by DCs. Transforming growth factor $\beta$ (TGF $\beta$ ) regulates the NK cell response by reducing IFN $\gamma$ production ${ }^{47}$. Interestingly, $\mathrm{CD}^{+} \mathrm{T}$ cells can also shape the early adaptive immune response to leishmaniasis by producing IFN $\gamma$ in lymph nodes, but whether $\mathrm{CD}^{+} \mathrm{T}$ cells are required for this immune response depends on the magnitude of the initial infection $^{48}$. For example, C57BL/6 mice develop a $\mathrm{T}_{\mathrm{H}} 1$-type response and lesions heal in the absence of $\mathrm{CD}^{+} \mathrm{T}$ cells following a high infectious $L$. major dose, whereas $\mathrm{CD}^{+} \mathrm{T}$ cells producing IFN $\gamma$ are required to promote $\mathrm{CD} 4^{+} \mathrm{T}_{\mathrm{H}} 1$ cell development after a low infectious dose $^{48,49}$ (FIG. 3a).

T cell-mediated immunity. As mentioned above, $\mathrm{CD} 4^{+}$ $\mathrm{T}_{\mathrm{H}} 1$ cells are essential for controlling Leishmania, and following infection these cells are recruited to the cutaneous lesions where they produce IFN $\gamma$ to activate macrophages. Intravital imaging studies have demonstrated that $\mathrm{CD}^{+} \mathrm{T}$ cells are not evenly distributed in Leishmania lesions and T cells do not interact with all infected cells ${ }^{50}$. However, the produced IFN $\gamma$ has a long-range effect, enabling NO production by infected cells that are at least $80 \mu \mathrm{m}$ away ${ }^{51}$. In addition to $\mathrm{CD} 4^{+} \mathrm{T}$ cells, a poorly understood population of double-negative T cells which do not express CD4 or CD8 but do express CD3 and the $\alpha \beta \mathrm{T}$ cell receptor - is also expanded in patients with cutaneous leishmaniasis ${ }^{52}$. A similar double-negative T cell population exists in L. major-infected mice ${ }^{53}$. These cells are phenotypically distinct from classical CD $4^{+}$ $\mathrm{T}$ cells as they have an innate cell-like gene expression profile, but, similar to $\mathrm{CD} 4^{+} \mathrm{T}$ cells, they proliferate and produce IFN $\gamma$ upon MHC class II antigen recognition of Leishmania and thereby contribute to immunity ${ }^{53}$.

The resolution of a primary infection with Leishmania leads to long-lasting immunity to reinfection that is mediated primarily by $\mathrm{CD} 4^{+} \mathrm{T}$ cells ${ }^{54}$. However, a low number of parasites remain following lesion resolution due to an IL-10-mediated downregulation of the immune response ${ }^{55}$. These persistent parasites maintain a population of Leishmania-specific effector $\mathrm{CD} 4^{+} \mathrm{T}$ cells that can respond immediately upon re-challenge. Some of these circulating $\mathrm{T}$ cells have recently been characterized as short-lived CD4 ${ }^{+}$LY6 $6 \mathrm{C}^{+}$Tbet $^{\text {hi }}$ T cells that upon re-challenge migrate to the challenge site and promote parasite killing ${ }^{56}$. In addition to these short-lived effector T cells, Leishmania-specific T cells with an effector memory $\mathrm{T}\left(\mathrm{T}_{\mathrm{EM}}\right)$ cell phenotype exist (BOX 1), but it is currently unclear whether they survive in the absence of persistent parasites ${ }^{57}$. However, Leishmania infection 


\section{Box $1 \mid \mathrm{CD}^{+} \mathrm{T}$ cell subsets}

Effector T cells. A subset of short-lived T cells that circulate in the blood and can enter tissues. Identified as CD44 ${ }^{+}, \mathrm{CD}_{2} \mathrm{~L}^{\text {low }}$, interleukin-7 receptor (IL-7R) $)^{+-}$and $\mathrm{LY} 6 \mathrm{C}^{+}$.

Effector memory $T$ cells ( $T_{E M}$ cells). A subset of long-lived $T$ cells that circulate in the blood and can enter tissues. Identified as $\mathrm{CD}_{4} 4^{+}, \mathrm{CD} 62 \mathrm{~L}^{\text {low }}$ and IL-7R .

Central memory $T$ cells $\left(T_{C M}\right.$ cells). Long-lived $T$ cells that circulate in the blood and can enter secondary lymphoid organs (lymph nodes). Identified as CD44, CD62 $\mathrm{L}^{\text {hi }}$ and CC chemokine receptor 7 (CCR7) ${ }^{+}$. Upon secondary stimulation, $\mathrm{T}_{\mathrm{CM}}$ cells differentiate into effector T cells.

Tissue-resident memory $T$ cells $\left(T_{R M}\right.$ cells). T cells that enter the tissues and remain there. Identified as $\mathrm{CD}_{4} 4^{+}, \mathrm{CD}_{22} \mathrm{~L}^{\text {low }}$, and probably $\mathrm{CD} 69^{+}, \mathrm{CCR}^{-}$, and in the skin, $\mathrm{P}$-selectin ligand $^{\text {hi }}$ and E-selectin ligand ${ }^{\text {hi. }}$.

\section{Immune responses driving pathogenesis}

Multiple pathways can contribute to disease severity following infection with Leishmania, and the type of immune response that develops is crucial in determining disease outcome (that is, self-healing or chronic disease) (FIG. 1). The virulence factors that contribute to the differential outcome of infection with different Leishmania spp. or strains are still poorly defined. However, it was recently demonstrated that a double-stranded RNA virus present in some Leishmania isolates might contribute to more severe disease in cutaneous leishmaniasis ${ }^{68}$. Although this Leishmania virus was first identified in the late $1980 \mathrm{~s}^{69}$, its biological importance has been only recently recognized. By comparing Leishmania guyanensis strains that harbour different levels of this virus, it was demonstrated that higher viral loads are associated with the induction of a pro-inflammatory response marked by increased production of CXC-chemokine ligand 10 (CXCL10), TNF, IL-6 and IFN $\beta^{68}$. The importance of these findings was recently demonstrated in a study showing that the presence of the virus in Leishmania isolates from infected patients could predict treatment failure, symptomatic relapse and development of mucosal leishmaniasis ${ }^{70-72}$. However, the presence of this RNA virus is limited to specific regions in South America; thus, this RNA virus is only one of the virulence factors that promotes severe disease, because parasite metastasis and treatment failure still occurs in areas where the RNA virus infection is not observed ${ }^{73,74}$.

Limited control of parasite replication. Most Leishmaniainfected BALB/c mice develop progressive lesions with increased parasite replication, with some exceptions $\mathrm{s}^{75-78}$ (TABLE 1). The severity of the lesion in these mice is partly dependent on the development of a $\mathrm{CD} 4^{+} \mathrm{T}_{\mathrm{H}}$ 2-type response, as lesions resolve following treatment with an IL-4-specific $\mathrm{mAb}^{79}$. However, IL-10-deficient BALB/c mice can also resolve a $L$. major infection, suggesting that IL-10 promotes disease in susceptible mice ${ }^{80}$. Indeed, even in L. major-resistant strains, such as C57BL/6, control of $L$. major infection can take weeks, and a low number of parasites persist after the lesion resolves. This protracted parasite control and persistence following L. major infection is largely due to the production of IL-10, which can be produced by myeloid cells, regulatory $\mathrm{T}\left(\mathrm{T}_{\text {reg }}\right)$ cells and conventional $\mathrm{T}$ cells $\mathrm{s}^{5,81,82}$.

High levels of IL-4 are not observed in patients with severe diffuse cutaneous leishmaniasis, suggesting that $\mathrm{CD}^{+} \mathrm{T}_{\mathrm{H}} 2$-type responses may be less important for disease progression in humans. Instead, other factors contribute to the lack of an appropriate immune response against $L$. amazonensis and L. mexicana, which cause diffuse cutaneous leishmaniasis. Indeed, C57BL/6 mice that normally self-heal following infection with $L$. major fail to resolve an infection with L. mexicana or L. amazonensis parasites due to a defective priming of $\mathrm{T}_{\mathrm{H}}$ 1-type responses $^{83}$. This lack of disease resolution may be due to an enhanced IL-10 production, leading to inadequate DC activation and IL-12 production $^{84,85}$. In addition, recent work has shown that the level of arginase I which is essential for parasite replication - and other suppressive factors, such as prostaglandin $\mathrm{E}_{2}$ and TGF $\beta$, 


\section{Box 2 | Leishmania vaccines}

Although several strategies have been pursued to induce protection against Leishmania infection, there is currently no effective vaccine for either cutaneous or visceral leishmaniasis. The most successful way to prevent leishmaniasis is infection with live parasites; this procedure, called leishmanization ${ }^{130}$, was used for centuries to protect against disfiguring lesions on exposed parts of the body. Although usually effective, leishmanization can be associated with loss of parasite virulence, difficulty in standardization and, most importantly, the development of non-healing lesions. In addition, because the parasites are never cleared, individuals are at risk of recurrent infections if they become immunocompromised. Hence, this approach is not used today. Nevertheless, the success of leishmanization provided support for the idea that a vaccine is possible for leishmaniasis. However, the gap from a live vaccine to more traditional vaccines has turned out to be much greater than initially thought.

Attempts to vaccinate with whole killed parasites, attenuated live parasites, parasite proteins, subunit recombinant vaccines, vectored vaccines and DNA vaccines have had limited success ${ }^{131}$. Despite demonstrations of safety, multiple phase III vaccine trials with killed whole parasites were unsuccessful ${ }^{132}$. This lack of success is partially due to the inability to generate long-term cell-mediated immunity by traditional vaccines and adjuvants. With advancements in the understanding of innate immune responses, newer adjuvants are being developed that may overcome this problem ${ }^{133,134}$. Another issue that has delayed the development of a leishmaniasis vaccine is the lack of an immunodominant antigen recognized by $\mathrm{CD} 4^{+} \mathrm{T}$ cells. However, it was recently discovered that the Leishmania protein glycosomal phosphoenolpyruvate carboxykinase is an immunodominant antigen recognized by $\mathrm{CD} 4^{+} \mathrm{T}$ cells and is conserved in many different Leishmania parasites. Importantly, immunization with this protein provided significant protection against both cutaneous and visceral leishmaniasis in animal models ${ }^{135}$. As Leishmania is transmitted by sand flies, several studies have also investigated the potential role of sand fly salivary proteins in vaccines ${ }^{136}$. For example, vaccination with a sand fly salivary protein induced significant protection against sand fly transmission of Leishmania major in rhesus macaques ${ }^{137}$. This result suggests that incorporating sand fly salivary proteins in a vaccine may promote better protection.

These data highlight the continued efforts being made towards developing a leishmanial vaccine. We now have an increased understanding of the memory T cells to target ${ }^{56,61}$, new adjuvants in development ${ }^{133,134}$ and identified an immunodominant antigen shared by many Leishmania spp. Together with novel approaches for vaccine design ${ }^{137}$, including a better understanding of the role of the sand fly in challenge experiments ${ }^{128}$ and the potential role of sand fly proteins as part of a vaccine ${ }^{136}$, a leishmanial vaccine remains an achievable goal.

\section{Perforin}

A calcium-sensitive membranolytic protein that is found in cytoplasmic granules of cytotoxic T lymphocytes and natural killer cells. are increased in plasma and skin biopsies from patients with diffuse cutaneous leishmaniasis ${ }^{86}$. However, how certain Leishmania spp. enhance disease by dampening the immune response, whereas others do so by exacerbating immune responses, remains unclear.

The role of $T_{H}$ cell responses. Although $\mathrm{T}_{\mathrm{H}} 1$-type responses are required to control Leishmania infection, the $\mathrm{T}_{\mathrm{H}} 1$ cytokines TNF and IFN $\gamma$ have also been implicated in its pathogenesis. Similar to other infections, TNF has a dual role in the outcome of infection. TNF is a cofactor for macrophage activation, and TNF receptor-deficient mice are more susceptible to $L$. major infections ${ }^{87,88}$. However, high levels of TNF are associated with more severe disease and lesion chronicity in patients with cutaneous leishmaniasis ${ }^{89}$. In support of a causative role, clinical trials revealed that a combination of antiparasitic drugs and TNF inhibitors leads to better outcomes in patients ${ }^{90}$. Similar to TNF, high levels of IFN $\gamma$ are seen in patients with more severe disease, such as in mucosal leishmaniasis ${ }^{3}$. However, whether IFN $\gamma$ exacerbates pathology directly is not known.
$\mathrm{CD} 4{ }^{+} \mathrm{T}_{\mathrm{H}} 17$ cells protect against certain bacteria and fungi, and are major players in mediating the immunopathology associated with autoimmune diseases. $\mathrm{BALB} / \mathrm{c}$ mice have high levels of IL-17 after infection with $L$. major, and IL-17 deficiency promotes better control of disease ${ }^{91}$. Mimicking the low levels of IL-10 observed in patients' lesions ${ }^{92}$, blocking IL-10 signalling in mice increases IL-17 production and causes more severe disease following infection with high doses of $L$. major, which is reversed by neutralizing IL-17 (REF. 93). Similarly, IL-17 levels correlate with the inflammatory response in the skin of patients with cutaneous and mucosal leishmaniasis ${ }^{9495}$. Most of the human-based work studying the pathogenesis induced by IL-17 has been performed in patients with $L$. braziliensis infection, and the role that IL-17 has in cutaneous leishmaniasis caused by other Leishmania spp. is unexplored.

The role of cytotoxic $\mathrm{CD}^{+} T$ cells in pathogenesis. Cytotoxicity was first associated with disease severity in patients with L. amazonensis infection in the late 1990s. Studies showed that peripheral blood cells from patients with mucosal leishmaniasis exhibited higher cytolytic capacity than those from healthy controls and patients with cutaneous leishmaniasis ${ }^{96}$. In L. braziliensisinfected patients, as disease progresses from early (non-ulcerated) lesions to late (ulcerated) lesions the ratio between $\mathrm{CD} 4^{+}$and $\mathrm{CD} 8^{+} \mathrm{T}$ cells changes, and more $\mathrm{CD} 8^{+} \mathrm{T}$ cells are found in patients with ulcerated lesions ${ }^{97}$. In contrast to $\mathrm{CD} 4^{+} \mathrm{T}$ cells that express IFN $\gamma$, $\mathrm{CD}^{+} \mathrm{T}$ cells in lesions have a cytotoxic profile marked by granzyme expression ${ }^{92,98,99}$. Genome-wide transcriptional profiling of lesions from L. braziliensis-infected patients has confirmed that cytotoxicity is a major signature of $L$. braziliensis lesions ${ }^{100}$. In addition, the expression of genes associated with cytolytic function and genes involved in skin barrier function were negatively correlated, suggesting that cytotoxicity and loss of skin integrity occur together in L. braziliensis disease in humans ${ }^{100}$.

The observation that $\mathrm{CD} 8^{+} \mathrm{T}$ cells in the skin correlate with disease severity in patients was unexpected because $\mathrm{CD} 8^{+} \mathrm{T}$ cells can promote resistance in mice ${ }^{49}$. However, Leishmania infection of recombinationactivating gene ( $R a g)$-deficient mice that have been reconstituted with $\mathrm{CD} 8^{+} \mathrm{T}$ cells leads to both severe non-healing primary and metastatic lesions, which are unrelated to the parasite burden ${ }^{49,101}$. This increased pathology is due to the cytolytic activity of the $\mathrm{CD}^{+}$ $\mathrm{T}$ cells in the skin, because $\mathrm{CD} 8^{+} \mathrm{T}$ cells lacking perforin are not pathogenic in this model ${ }^{101}$. The cytolytic activity of $\mathrm{CD} 8^{+} \mathrm{T}$ cells during Leishmania infection has also been visualized by spinning disc confocal microscopy ${ }^{101}$ (see Supplementary information S1 (movie)). These findings show that cytolytic $\mathrm{CD} 8^{+} \mathrm{T}$ cells are pathogenic when a large number is recruited to Leishmania lesions. Furthermore, previous infections with pathogens known to induce a large $\mathrm{CD} 8^{+} \mathrm{T}$ cell response (such as lymphocytic choriomeningitis virus or Listeria monocytogenes) were associated with increased lesion development following subsequent challenge 


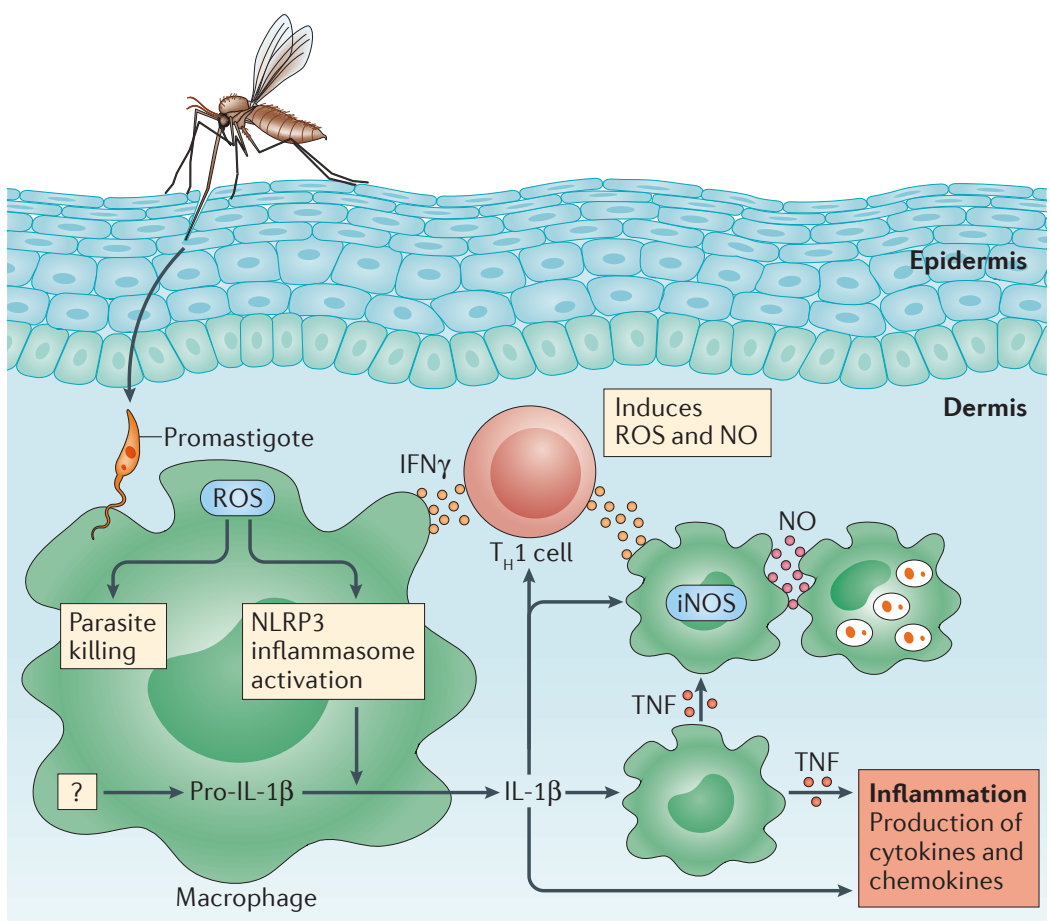

Figure 4 | IL-1 $\beta$ and TNF can be protective or pathogenic in cutaneous leishmaniasis. Phagocytosis of Leishmania parasites by innate cells leads to the production of reactive oxygen species (ROS). ROS can induce parasite elimination as well as activate the NLRP3 (NOD-, LRR- and pyrin domain-containing 3) inflammasome. The factor (or factors) inducing pro-interleukin-1 $\beta$ (IL-1 $\beta$ ) production in the skin is currently unknown. Nevertheless, pro-IL-1 $\beta$ is processed by the inflammasome in the skin and its mature form can function in several ways during Leishmania infection. IL-1 $\beta$ is important in Thelper $1\left(\mathrm{~T}_{\mathrm{H}} 1\right)$ cell expansion by promoting IL-12 production. Also, IL-1 $\beta$ induces nitric oxide (NO) activation either directly, by activating macrophages, or indirectly, by promoting $\mathrm{T}_{\mathrm{H}} 1$-type responses and interferon- $\gamma$ (IFN $\gamma$ ) production. IL-1 $\beta$ can also induce tumour necrosis factor (TNF), which can be protective by synergizing with IFN $\gamma$ and thus increasing inducible NO synthase (iNOS) production in innate cells. NO can promote parasite control in the iNOS-expressing cell, but it can also diffuse through tissue and act on neighbouring cells. In contrast to their protective roles, IL-1 $\beta$ and TNF can also enhance the production of several chemokines and cytokines and promote the expression of adhesion molecules, leading to the amplified recruitment of cells from the blood. This enhanced inflammation results in tissue destruction and disease severity.

\section{NKG2D}

(Natural killer group 2 member D). A protein expressed on the surface of activated natural killer and CD8 + T cells that binds to self-ligands that are induced following stress, development of malignancy and infection. Interactions between NKG2D and its ligands can induce lysis of the NKG2D ligand-expressing cell. with $L$. major ${ }^{102}$. Notably, bystander $\mathrm{CD}^{+} \mathrm{T}$ cells that express the NKG2D-activating receptor lysed NKG2D ligand-expressing cells in the lesions. In this model, inflammation is dependent on $\mathrm{CD}^{+} \mathrm{T}$ cells inducing cell death in an NKG2D-dependent manner. Consistent with the ability of bystander $\mathrm{CD}^{+} \mathrm{T}$ cells to contribute to the immune response within Leishmania lesions, Toxoplasma-specific CD8 ${ }^{+} \mathrm{T}$ cells have been identified in lesions of L. braziliensis-infected patients ${ }^{103}$. As humans have been exposed to a variety of pathogens that might leave an expanded pool of memory CD8 ${ }^{+}$ $\mathrm{T}$ cells, these results uncover an additional factor that may influence the development of immunopathology in human cutaneous leishmaniasis.

How $\mathrm{CD}^{+} \mathrm{T}$ cells can have both protective and pathological roles is currently unclear. It seems most likely that this dual role depends on whether the $\mathrm{CD} 8^{+}$
T cells are cytolytic or produce IFN $\gamma$, and further study is needed to determine why $\mathrm{CD}^{+} \mathrm{T}$ cells appear to be preferentially cytotoxic in the skin during leishmaniasis (FIG. 3a,b). Furthermore, mouse cytotoxic T cells do not seem to kill Leishmania, which could be due to the absence of granulysin in mouse $\mathrm{CD}^{+} \mathrm{T}$ cells ${ }^{104}$. Finally, although it is also unclear how cytolysis drives pathology, transcriptional analysis of lesions suggests that it may be due to activation of the inflammasome by dead cells, which leads to the production of pro-inflammatory IL- $1 \beta^{100}$.

Inflammasome activation and IL-1 $\beta$. Similar to TNF, IL-1 $\beta$ can lead to protective or pathogenic effects during Leishmania infection (FIG. 4). On the one hand, shortterm treatment with IL- $1 \beta$ at the beginning of $L$. major infection in C57BL/6 mice provides protection ${ }^{105}$, and the absence of IL-1 $\beta$ in L. amazonensis-infected mice leads to exacerbated disease $\mathrm{e}^{106}$. On the other hand, continuous IL-1 $\beta$ treatment of $L$. major-infected mice leads to more severe disease ${ }^{105}$. IL- $1 \beta$ also exacerbates lesions in L. major-infected BALB/c mice ${ }^{107,108}$, and can promote pathology in C57BL/6 mice by inducing the development of $\mathrm{T}_{\mathrm{H}} 17$ cells ${ }^{93}$. Furthermore, IL-1 $\beta$ was recently shown to be responsible for the disease severity in C57BL/6 mice after infection with the nonhealing L. major Seidman strain ${ }^{25}$. Only a few studies have investigated the role of IL-1 in Leishmania-infected patients and these studies have indicated that IL-1 also contributes to disease in humans. For example, during $L$. mexicana infection, IL- $1 \beta$ expression correlates with disease severity ${ }^{109}$, and $I L 1 B$ mRNA levels positively correlate with the expression of cytolytic genes associated with pathology in L. braziliensis-infected patients ${ }^{100}$. IL-1 can also enhance inflammation by promoting TNF production ${ }^{110}$. Hence, at the T cell-priming phase of infection, IL-1 $\beta$ may enhance the differentiation of protective $\mathrm{CD}^{+} \mathrm{T}$ cells, whereas excessive production of IL- $1 \beta$ during the chronic phase of infection is detrimental to the host.

IL- $1 \beta$ activation is primarily accomplished by caspase 1-mediated cleavage following inflammasome activation. In addition to IL- $1 \beta$, the inflammasome pathway is a transcriptional signature of L. braziliensis infection in humans ${ }^{100}$. In mice, the inflammasome has been implicated in either protection or pathogenesis of leishmaniasis depending on the mouse model and the parasite species used. On the one hand, IL- $1 \beta$ processing by the inflammasome appears to promote NO production in L. amazonensis-infected mice, although not sufficiently for the mice to heal ${ }^{106}$. On the other hand, pathology induced by infection with the non-healing L. major Seidman strain is dependent on the inflammasome, as mice deficient in inflammasome components display increased control of the infection ${ }^{25}$. IL-18 is also processed by the inflammasome, and it can also be either protective or pathogenic in L. major infection depending on the mouse genetic background. In C57BL/6 mice, IL-18 can synergize with IL-12 and promote $\mathrm{T}_{\mathrm{H}} 1$-type responses, whereas in $\mathrm{BALB} / \mathrm{c}$ mice IL-18 enhances $\mathrm{T}_{\mathrm{H}} 2$ cell development by inducing the production of 
IL-4 (REFS 111-113). In L. major-infected BALB/c mice, inflammasome deficiency reduces lesion sizes due to a defect in IL-18 production ${ }^{111}$. These results raise the question of how parasites contribute to inflammasome activation. Studies published to date indicate that Leishmania may not activate the inflammasome directly and in certain cases may even inhibit the inflammasome $^{114}$. Leishmania parasites are poor inducers of IL- $1 \beta$ alone, but do promote IL- $1 \beta$ when macrophages are also stimulated with lipopolysaccharide ${ }^{25,106}$. The induction of ROS after parasite phagocytosis through C-type lectin receptors may indirectly induce inflammasome activation in both mice and human macrophages ${ }^{115}$. Hence, although inflammasome activation and maturation of IL- $1 \beta$ certainly plays a part in Leishmania infection, how the inflammasome is activated in cutaneous leishmaniasis is less clear.

\section{Regulation of the immune response}

The role of $T_{\text {reg }}$ cells and $I L-10 . T_{\text {reg }}$ cells have been observed in lesions from Leishmania-infected patients, and these purified $\mathrm{T}_{\text {reg }}$ cells can be suppressive in vitro ${ }^{116,117}$. However, some studies have found that $\mathrm{T}_{\text {reg }}$ cell function is impaired in chronic cutaneous leishmaniasis caused by Leishmania panamensis or L. braziliensis ${ }^{118}$. Although there is still much to be learned regarding the role of $\mathrm{T}_{\text {reg }}$ cells in humans, their role in mice has been explored in several studies. $\mathrm{T}_{\text {reg }}$ cells from lesions of L. major-infected C57BL/6 mice respond to L. major antigen and accumulate rapidly in a CCR5-dependent manner at the site of infection and suppress $\mathrm{CD} 4^{+} \mathrm{T}$ cell activity, which favours parasite persistence ${ }^{55,119,120}$. Moreover, depletion of $\mathrm{T}_{\text {reg }}$ cells results in sterile immunity; consequently, mice lose their normal resistance to reinfection with L. major ${ }^{55} . \mathrm{T}_{\text {reg }}$ cells are important both during primary infection with L. major and in secondary infections, because induction of $\mathrm{T}_{\text {reg }}$ cells can render otherwise immune mice susceptible to infection ${ }^{121}$ or reactivate a secondary infection ${ }^{122}$. However, a different role for $\mathrm{T}_{\text {reg }}$ cells is seen following infection with New World species of Leishmania. For example, transfer of $\mathrm{T}_{\text {reg }}$ cells from an infected mouse to a naive mouse immediately before infection with L. amazonensis reduces lesion development ${ }^{123}$, which suggests that $\mathrm{T}_{\text {reg }}$ cells control immunopathological responses. In addition, $\mathrm{T}_{\text {reg }}$ cells inhibit disease progression in L. panamensis infections by downregulating pathological responses and by reducing the parasite load ${ }^{124}$. These findings demonstrate the difficulty of making generalized statements about the role of $\mathrm{T}_{\text {reg }}$ cells in regulating cutaneous leishmaniasis, as the immune response is probably influenced by both the parasite species and host genetics.

Although $\mathrm{T}_{\text {reg }}$ cells function in both an IL-10-

Inflammasome
An innate immune sensor that recognizes pathogens and self molecules released during tissue damage. It is a molecular complex of several proteins; once assembled, the

inflammasome processes pro-interleukin-1 (pro-IL-1) and pro-IL-18 to their active forms. as circulating monocytes ${ }^{125,126}$. Regardless of the source, all of the studies indicate that IL-10 is an important regulator of immunity in leishmaniasis.

\section{Conclusion and future perspectives}

Here, we have summarized recent advances in our understanding of the immune response to cutaneous leishmaniasis and, when possible, integrated our knowledge from mouse models to human disease. We have learned a great deal about the immune system from studies using mouse models of cutaneous leishmaniasis; however, those advances have yet to substantively change treatment for this disease or lead to an effective vaccine. New therapies for cutaneous leishmaniasis are urgently needed because most of the drugs currently used to treat patients are either toxic or expensive, and may require several rounds of treatment. Moreover, the treatments have high failure rates, possibly because they only target the parasite, which may not alleviate the immunopathological responses that drive disease in many forms of cutaneous leishmaniasis. Thus, in addition to developing new drugs to target the parasite, research efforts should focus on testing immunotherapies that could reduce the severity of pathology seen in cutaneous leishmaniasis. Several of the drugs being developed for other chronic inflammatory diseases, such as those that inhibit TNF, IL-1 or cytotoxicity, might be useful for such therapy and could be used in combination with antiparasitic drugs. Furthermore, recent work has demonstrated the influence of the skin microbiome in the pathology induced by Leishmania ${ }^{127}$ and, although a full understanding of how skin commensals alter disease is in its infancy, there is strong evidence to indicate that the microbiota present in the skin affects several diseases, one of which is likely to be cutaneous leishmaniasis. As our knowledge grows in this area, it is possible that we will be able to incorporate that information into new treatments.

A long-term goal for Leishmania research is to develop an effective vaccine, which has so far been unsuccessful (BOX 2). The development of mouse models that better mimic the wide spectrum of human cutaneous leishmaniasis is important, as well as the development of sand fly challenge models that better mimic natural infection ${ }^{128}$. Currently, the best immune protection requires persistent parasites, which is a clear hurdle for vaccine development. Furthermore, whether we need a vaccine that provides complete protection is an important decision because it is currently unlikely that any vaccine will provide sterile immunity. Thus, the main goal of vaccine development in leishmaniasis might be to reduce the time of healing and avoid the most severe clinical forms of the disease. Important discoveries of protective antigens in leishmaniasis and the development of newer and better adjuvants will continue, but the key issue that remains is whether vaccination can induce long-term memory in leishmaniasis. Advances in our understanding of memory $\mathrm{T}$ cells in general ${ }^{129}$, and the discovery that $\mathrm{T}_{\mathrm{CM}}$ and $\mathrm{T}_{\mathrm{RM}}$ cells can provide longer term protection in leishmaniasis $^{58,61}$, might form the basis for future vaccine strategies in which longer-lived $\mathrm{T}$ cells are targeted that can lessen the development and severity of cutaneous leishmaniasis. 
1. Alvar, J. et al. Leishmaniasis worldwide and global estimates of its incidence. PLOS ONE 7, e35671 (2012).

2. Carvalho, E. M., Barral, A., Costa, J. M., Bittencourt, A. \& Marsden, P. Clinical and immunopathological aspects of disseminated cutaneous leishmaniasis. Acta Trop. 56, 315-325 (1994).

3. Bacellar, O. et al. Up-regulation of Th1-type responses in mucosal leishmaniasis patients. Infect. Immun. $\mathbf{7 0}$ 6734-6740 (2002)

4. Turk, J. L. \& Bryceson, A. D. Immunological phenomena in leprosy and related diseases. Adv. Immunol. 13 209-266 (1971)

5. Scott, P., Natovitz, P., Coffman, R. L., Pearce, E. \& Sher, A. Immunoregulation of cutaneous leishmaniasis. $T$ cell lines that transfer protective immunity or exacerbation belong to different T helper subsets and respond to distinct parasite antigens. J. Exp. Med. 168, 1675-1684 (1988)

6. Heinzel, F. P., Sadick, M. D., Holaday, B. J., Coffman, R. L. \& Locksley, R. M. Reciprocal expression of interferon gamma or interleukin 4 during the resolution or progression of murine leishmaniasis. Evidence for expansion of distinct helper $\mathrm{T}$ cell subsets. J. Exp. Med. 169, 59-72 (1989)

7. Kaye, P. \& Scott, P. Leishmaniasis: complexity at the host-pathogen interface. Nat. Rev. Microbiol. 9 , 604-615 (2011)

8. Sacks, D. \& Kamhawi, S. Molecular aspects of parasite-vector and vector-host interactions in leishmaniasis. Annu. Rev. Microbiol. 55, 453-483 (2001).

9. Belkaid, Y. et al. A natural model of Leishmania major infection reveals a prolonged "silent" phase of parasite amplification in the skin before the onset of lesion formation and immunity. J. Immunol. 165, 969-977 (2000).

10. Ribeiro-Gomes, F. L. et al. Site-dependent recruitment of inflammatory cells determines the effective dose of Leishmania major. Infect. Immun. 82, 2713-2727 (2014).

11. Peters, N. C. et al. In vivo imaging reveals an essential role for neutrophils in leishmaniasis transmitted by sand flies. Science 321, 970-974 (2008).

This paper provides the first visualization of the rapid recruitment of neutrophils to the site of Leishmania infection.

12. Guimaraes-Costa, A. B. et al. Leishmania amazonensis promastigotes induce and are killed by neutrophil extracellular traps. Proc. Natl Acad. Sci. USA 106 6748-6753 (2009).

13. Rochael, N. C. et al. Classical ROS-dependent and early/rapid ROS-independent release of neutrophil extracellular traps triggered by Leishmania parasites. Sci. Rep. 5, 18302 (2015)

14. Chagas, A. C. et al. Lundep, a sand fly salivary endonuclease increases Leishmania parasite survival in neutrophils and inhibits XIla contact activation in human plasma. PLoS Pathog. 10, e1003923 (2014).

15. Novais, F. O. et al. Neutrophils and macrophages cooperate in host resistance against Leishmania braziliensis infection. J. Immunol. 183, 8088-8098 (2009).

16. de Souza Carmo, E. V., Katz, S. \& Barbieri, C. L. Neutrophils reduce the parasite burden in Leishmania (Leishmania) amazonensis-infected macrophages. PLOS ONE 5, e13815 (2010).

17. Savill, J., Dransfield, I., Gregory, C. \& Haslett, C. A blast from the past: clearance of apoptotic cells regulates immune responses. Nat. Rev. Immunol. 2 965-975 (2002)

18. van Zandbergen, G. et al. Cutting edge: neutrophil granulocyte serves as a vector for Leishmania entry into macrophages. J. Immunol. 173, 6521-6525 (2004).

19. Hurrell, B. P. et al. Rapid sequestration of Leishmania mexicana by neutrophils contributes to the development of chronic lesion. PLoS Pathog. 11, e1004929 (2015).

This study uses neutropaenic Genista mice to demonstrate that neutrophils promote the development of chronic $L$. mexicana lesions.

20. Charmoy, M. et al. Neutrophil-derived CCL3 is essential for the rapid recruitment of dendritic cells to the site of Leishmania major inoculation in resistant mice. PLoS Pathog. 6, e 1000755 (2010).

21. Ribeiro-Gomes, F. L., Peters, N. C., Debrabant, A. $\&$ Sacks, D. L. Efficient capture of infected neutrophils by dendritic cells in the skin inhibits the early antileishmania response. PLoS Pathog. 8, e1002536 (2012).
22. Ribeiro-Gomes, F. L. et al. Apoptotic cell clearance of Leishmania major-infected neutrophils by dendritic cells inhibits CD8 ${ }^{+}$T-cell priming in vitro by Mer tyrosine kinase-dependent signaling. Cell Death Dis. 6 e2018 (2015)

23. Tacchini-Cottier, F. et al. An immunomodulatory function for neutrophils during the induction of a $\mathrm{CD}^{+}{ }^{+} \mathrm{Th} 2$ response in $\mathrm{BALB} / \mathrm{c}$ mice infected with Leishmania major. J. Immunol. 165, 2628-2636 (2000).

24. Ordonez-Rueda, D. et al. A hypomorphic mutation in the Gfi 1 transcriptional repressor results in a novel form of neutropenia. Eur. J. Immunol. 42, 2395-2408 (2012)

25. Charmoy, M. et al. The NIrp3 inflammasome, $\mathrm{IL}-1 \beta$, and neutrophil recruitment are required for susceptibility to a non-healing strain of Leishmania major in C57BL/6 mice. Eur. J. Immunol. 46, 897-91 (2016)

This study suggests that the inflammasome and IL-1 $\beta$ are required for severe disease in chronic leishmaniasis.

26. Ng, L. G. et al. Migratory dermal dendritic cells act as rapid sensors of protozoan parasites. PLoS Pathog. 4. e 1000222 (2008)

27. Goncalves, R., Zhang, X., Cohen, H., Debrabant, A \& Mosser, D. M. Platelet activation attracts a subpopulation of effector monocytes to sites of Leishmania major infection. J. Exp. Med. 208 1253-1265 (2011).

This paper is the first to demonstrate that inflammatory monocytes are rapidly recruited to the site of infection and kill the Leishmania parasite.

28. Sato, N. et al. CC chemokine receptor (CCR) 2 is required for Langerhans cell migration and localization of Thelper cell type 1 (Th1)-inducing dendritic cells Absence of CCR2 shifts the Leishmania major-resistant phenotype to a susceptible state dominated by Th2 cytokines, B cell outgrowth, and sustained neutrophilic inflammation. J. Exp. Med. 192, 205-218 (2000).

29. Nacy, C. A., Meltzer, M. S., Leonard, E. J. \& Wyler, D. J. Intracellular replication and lymphokineinduced destruction of Leishmania tropica in $\mathrm{C} 3 \mathrm{H}$ / HeN mouse macrophages. J. Immunol. 127 2381-2386 (1981)

30. Matheoud, D. et al. Leishmania evades host immunity by inhibiting antigen cross-presentation through direct cleavage of the SNARE VAMP8. Cell Host Microbe 14 15-25 (2013)

31. Novais, F. O. et al. Human classical monocytes control the intracellular stage of Leishmania braziliensis by reactive oxygen species. J. Infect. Dis. 209 1288-1296 (2014)

32. Rocha, F. J., Schleicher, U., Mattner, J., Alber, G. \& Bogdan, C. Cytokines, signaling pathways, and effector molecules required for the control of Leishmania (Viannia) braziliensis in mice. Infect. Immun. 75 3823-3832 (2007)

33. Green, S. J., Crawford, R. M., Hockmeyer, J. T. Meltzer, M. S. \& Nacy, C. A. Leishmania major amastigotes initiate the L-arginine-dependent killing mechanism in IFN- $\gamma$-stimulated macrophages by induction of tumor necrosis factor- $\alpha$. J. Immunol. 145 4290-4297 (1990).

34. Bogdan, C., Moll, H., Solbach, W. \& Rollinghoff, M Tumor necrosis factor- $\alpha$ in combination with interferon- $\gamma$, but not with interleukin 4 activates murine macrophages for elimination of Leishmania major amastigotes. Eur. J. Immunol. 20, 1131-1135 (1990)

35. Olekhnovitch, R., Ryffel, B., Muller, A. J. \& Bousso, P. Collective nitric oxide production provides tissue-wide immunity during Leishmania infection. J. Clin. Invest. 124, 1711-1722 (2014).

36. Wei, X. Q. et al. Altered immune responses in mice lacking inducible nitric oxide synthase. Nature $\mathbf{3 7 5}$, 408-411 (1995).

37. Gantt, K. R. et al. Oxidative responses of human and murine macrophages during phagocytosis of Leishmania chagasi. J. Immunol. 167, 893-901 (2001).

38. Qadoumi, M., Becker, I., Donhauser, N., Rollinghoff, M. \& Bogdan, C. Expression of inducible nitric oxide synthase in skin lesions of patients with American cutaneous leishmaniasis. Infect. Immun. 70, 4638-4642 (2002)

39. Sypek, J. P. et al. Resolution of cutaneous eishmaniasis: interleukin 12 initiates a protective Thelper type 1 immune response. J. Exp. Med. 177 1797-1802 (1993).
40. Heinzel, F. P., Schoenhaut, D. S., Rerko, R. M. Rosser, L. E. \& Gately, M. K. Recombinant interleukin 12 cures mice infected with Leishmania major. J. Exp. Med. 177, 1505-1509 (1993).

41. Chatelain, R., Varkila, K. \& Coffman, R. L. IL-4 induces a Th2 response in Leishmania major-infected mice. J. Immunol. 148, 1182-1187 (1992).

42. von Stebut, E., Belkaid, Y., Jakob, T., Sacks, D. L. \& Udey, M. C. Uptake of Leishmania major amastigotes results in activation and interleukin 12 release from murine skin-derived dendritic cells: implications for the initiation of anti-Leishmania immunity. J. Exp. Med. 188, 1547-1552 (1998)

43. lezzi, G. et al. Lymph node resident rather than skinderived dendritic cells initiate specific T cell responses after Leishmania major infection. J. Immunol. 177 1250-1256 (2006)

44. Leon, B., Lopez-Bravo, M. \& Ardavin, C. Monocytederived dendritic cells formed at the infection site control the induction of protective T helper 1 responses against Leishmania. Immunity $\mathbf{2 6}$ 519-531 (2007)

A comprehensive study of the role of monocyte-derived DCs in priming a protective $T_{H} 1$-type response.

45. Scharton, T. M. \& Scott, P. Natural killer cells are a source of interferon $\gamma$ that drives differentiation of $\mathrm{CD} 4^{+} \mathrm{T}$ cell subsets and induces early resistance to Leishmania major in mice. J. Exp. Med. 178 567-577 (1993).

46. Bajenoff, M. et al. Natural killer cell behavior in lymph nodes revealed by static and real-time imaging. J. Exp. Med. 203, 619-631 (2006).

47. Laouar, Y., Sutterwala, F. S., Gorelik, L. \& Flavell, R. A Transforming growth factor- $\beta$ controls $T$ helper type 1 cell development through regulation of natural killer cell interferon- $\gamma$. Nat. Immunol. 6, 600-607 (2005).

48. Uzonna, J. E., Joyce, K. L. \& Scott, P. Low dose Leishmania major promotes a transient $\mathrm{T}$ helper cell type 2 response that is down-regulated by interferon $\gamma$-producing CD8 ${ }^{+}$T cells. J. Exp. Med. 199 1559-1566 (2004).

49. Belkaid, Y. et al. CD8 ${ }^{+} \mathrm{T}$ cells are required for primary immunity in C57BL/6 mice following low-dose, intradermal challenge with Leishmania major. J. Immunol. 168, 3992-4000 (2002).

50. Filipe-Santos, O. et al. A dynamic map of antigen recognition by CD4 T cells at the site of Leishmania major infection. Cell Host Microbe 6, 23-33 (2009).

51. Muller, A. J. et al. CD4 ${ }^{+} \mathrm{T}$ cells rely on a cytokine gradient to control intracellular pathogens beyond sites of antigen presentation. Immunity 37, 147-157 (2012).

52. Antonelli, L. R. et al. Disparate immunoregulatory potentials for double-negative (CD4- $\left.{ }^{-}{ }^{-} 8^{-}\right) \alpha \beta$ and $\gamma \delta$ $T$ cells from human patients with cutaneous leishmaniasis. Infect. Immun. 74, 6317-6323 (2006).

53. Mou, Z. et al. MHC class II restricted innate-like double negative $T$ cells contribute to optimal primary and secondary immunity to Leishmania major. PLoS Pathog. 10, e1004396 (2014).

54. Liew, F. Y., Hale, C. \& Howard, J. G. Immunologic regulation of experimental cutaneous leishmaniasis. V. Characterization of effector and specific suppressor T cells. J. Immunol. 128, 1917-1922 (1982).

55. Belkaid, Y., Piccirillo, C. A., Mendez, S., Shevach, E. M \& Sacks, D. L. CD $4{ }^{+} \mathrm{CD} 25^{+}$regulatory T cells control Leishmania major persistence and immunity. Nature 420, 502-507 (2002).

56. Peters, N. C. et al. Chronic parasitic infection maintains high frequencies of short-lived Ly6C + CD $4+$ effector $\mathrm{T}$ cells that are required for protection against re-infection. PLoS Pathog. 10, e 1004538 (2014).

A comprehensive study of the $\mathrm{CD} 4{ }^{+} \mathrm{LY}_{6 \mathrm{C}}{ }^{+}$effector $\mathrm{T}$ cells that provide rapid protection against Leishmania infection.

57. Colpitts, S. L., Dalton, N. M. \& Scott, P. IL-7 receptor expression provides the potential for long-term survival of both CD62 $\mathrm{L}^{\text {high }}$ central memory T cells and Th1 effector cells during Leishmania major infection. J. Immunol. 182, 5702-5711 (2009).

58. Zaph, C., Uzonna, J., Beverley, S. M. ¿ Scott, P. Central memory $T$ cells mediate long-term immunity to Leishmania major in the absence of persistent parasites. Nat. Med. 10, 1104-1110 (2004). This paper provides the first demonstration that CD4 ${ }^{+} T_{C M}$ cells can be maintained long-term in the absence of persistent parasites.

59. Colpitts, S. L. \& Scott, P. The early generation of heterogeneous $\mathrm{CD} 4{ }^{+} \mathrm{T}$ cell response to Leishmania major. J. Immunol. 185, 2416-2423 (2010). 
60. Mueller, S. N. \& Mackay, L. K. Tissue-resident memory T cells: local specialists in immune defence Nat. Rev. Immunol. 16, 79-89 (2016).

61. Glennie, N. D. et al. Skin-resident memory CD4+ $T$ cells enhance protection against Leishmania major infection. J. Exp. Med. 212, 1405-1414 (2015). This paper provides the first demonstration that infection with $L$. major generates skin-resident $\mathrm{CD}^{+} \mathrm{T}$ cells that promote immunity.

62. Muller, I., Kropf, P., Etges, R. J. \& Louis, J. A. Gamma interferon response in secondary Leishmania major infection: role of CD8 ${ }^{+} \mathrm{T}$ cells. Infect. Immun. 61, 3730-3738 (1993).

63. Bertholet, S. et al. Antigen requirements for efficient priming of $\mathrm{CD}^{+}{ }^{+} \mathrm{T}$ cells by Leishmania major-infected dendritic cells. Infect. Immun. 73, 6620-6628 (2005).

64. Gurunathan, S. et al. Vaccination with DNA encoding the immunodominant LACK parasite antigen confers protective immunity to mice infected with Leishmania major. J. Exp. Med. 186, 1137-1147 (1997).

65. Jayakumar, A. et al. TLR $1 / 2$ activation during heterologous prime-boost vaccination (DNA-MVA) enhances $\mathrm{CD} 8+\mathrm{T}$ Cell responses providing protection against Leishmania (Viannia). PLoS Negl. Trop. Dis. $\mathbf{5}$ e1204 (2011).

66. Rhee, E. G. et al. Vaccination with heat-killed leishmania antigen or recombinant leishmanial protein and $\mathrm{CpG}$ oligodeoxynucleotides induces long-term memory $\mathrm{CD}^{+}{ }^{+}$and $\mathrm{CD} 8{ }^{+} \mathrm{T}$ cell responses and protection against Leishmania major infection. J. Exp. Med. 195, 1565-1573 (2002).

67. Colmenares, M., Kima, P. E., Samoff, E., Soong, L. \& McMahon-Pratt, D. Perforin and $\gamma$ interferon are critical CD8 ${ }^{+}$T-cell-mediated responses in vaccineinduced immunity against Leishmania amazonensis infection. Infect. Immun. 71, 3172-3182 (2003).

68. Ives, A. et al. Leishmania RNA virus controls the severity of mucocutaneous leishmaniasis. Science 331, 775-778 (2011).

This report is the first to describe how a Leishmania RNA virus influences the severity of Leishmania infections.

69. Tarr, P. I. et al. LR1: a candidate RNA virus of Leishmania. Proc. Natl Acad. Sci. USA 85 9572-9575 (1988)

70. Bourreau, E. et al. Presence of Leishmania RNA virus 1 in Leishmania guyanensis increases the risk of firstline treatment failure and symptomatic relapse. J. Infect. Dis. 213, 105-111 (2016).

71. Adaui, V. et al. Association of the endobiont double stranded RNA virus LRV1 with treatment failure for human leishmaniasis caused by Leishmania braziliensis in Peru and Bolivia. J. Infect. Dis. 213, 112-121 (2016)

72. Cantanhede, L. M. et al. Further evidence of an association between the presence of Leishmania RNA virus 1 and the mucosal manifestations in tegumentary leishmaniasis patients. PLoS Negl. Trop. Dis. 9, e0004079 (2015).

73. Salinas, G., Zamora, M. Stuart, K. \& Saravia, N Leishmania RNA viruses in Leishmania of the Viannia subgenus. Am. J. Trop. Med. Hyg. 54, 425-429 (1996).

74. Pereira, L. et al. Severity of tegumentary leishmaniasis is not exclusively associated with Leishmania RNA virus 1 infection in Brazil. Mem. Inst. Oswaldo Cruz 108, 665-667 (2013).

75. McElrath, M. J., Kaplan, G., Nusrat, A. \& Cohn, Z. A. Cutaneous leishmaniasis. The defect in T cell influx in BALB/c mice. J. Exp. Med. 165, 546-559 (1987).

76. de Moura, T. R. et al. Toward a novel experimental model of infection to study American cutaneous leishmaniasis caused by Leishmania braziliensis. Infect. Immun. 73, 5827-5834 (2005).

77. Arredondo, B. \& Perez, H. Alterations of the immune response associated with chronic experimental leishmaniasis. Infect. Immun. 25, 16-22 (1979).

78. Nasseri, M. \& Modabber, F. Z. Generalized infection and lack of delayed hypersensitivity in BALB/c mice infected with Leishmania tropica major. Infect. Immun. 26, 611-614 (1979).

79. Sadick, M. D. et al. Cure of murine leishmaniasis with anti-interleukin 4 monoclonal antibody. Evidence for a $\mathrm{T}$ cell-dependent, interferon $\gamma$-independent mechanism. J. Exp. Med. 171, 115-127 (1990)

80. Kane, M. M. \& Mosser, D. M. The role of IL-10 in promoting disease progression in leishmaniasis. J. Immunol. 166, 1141-1147 (2001).

81. Anderson, C. F., Oukka, M., Kuchroo, V. J. \& Sacks, D. CD4 ${ }^{+}$CD 25-Foxp3- Th 1 cells are the source of IL-10-mediated immune suppression in chronic cutaneous leishmaniasis. J. Exp. Med 204, 285-297 (2007)

82. Miles, S. A., Conrad, S. M., Alves, R. G. Jeronimo, S. M. \& Mosser, D. M. A role for IgG immune complexes during infection with the intracellular pathogen Leishmania. J. Exp. Med. 201, 747-754 (2005)

83. Jones, D. E., Buxbaum, L. U. \& Scott, P. IL-4-independent inhibition of IL- 12 responsiveness during Leishmania amazonensis infection. J. Immunol. 165, 364-372 (2000)

84. Petritus, P. M., Manzoni-de-Almeida, D., Gimblet, C., Gonzalez Lombana, C. \& Scott, P. Leishmania mexicana induces limited recruitment and activation of monocytes and monocyte-derived dendritic cells early during infection. PLoS Negl. Trop. Dis. 6, e1858 (2012).

85. Soong, L. Modulation of dendritic cell function by Leishmania parasites. J. Immunol. 180, 4355-4360 (2008).

86. Franca-Costa, J. et al. Arginase I, polyamine, and prostaglandin E2 pathways suppress the inflammatory response and contribute to diffuse cutaneous leishmaniasis. J. Infect. Dis. 211, 426-435 (2015).

87. Wilhelm, P. et al. Rapidly fatal leishmaniasis in resistant C57BL/6 mice lacking TNF. J. Immunol. 166, 4012-4019 (2001)

88. Vieira, L. Q. et al. Mice lacking the TNF receptor p55 fail to resolve lesions caused by infection with Leishmania major, but control parasite replication. J. Immunol. 157, 827-835 (1996).

89. Melby, P. C. et al. Increased expression of proinflammatory cytokines in chronic lesions of human cutaneous leishmaniasis. Infect. Immun. 62, 837-842 (1994).

90. Ribeiro de Jesus, A., Luna, T., Pacheco de Almeida, R., Machado, P. R. \& Carvalho, E. M. Pentoxifylline down modulate in vitro $\mathrm{T}$ cell responses and attenuate pathology in Leishmania and HTLV-I infections. Int. Immunopharmacol 8, 1344-1353 (2008)

91. Lopez Kostka, S. et al. IL-17 promotes progression of cutaneous leishmaniasis in susceptible mice. J. Immunol. 182, 3039-3046 (2009).

92. Faria, D. R. et al. Decreased in situ expression of interleukin-10 receptor is correlated with the exacerbated inflammatory and cytotoxic responses observed in mucosal leishmaniasis. Infect. Immun. 73, 7853-7859 (2005)

93. Gonzalez-Lombana, C. et al. IL-17 mediates immunopathology in the absence of IL-10 following Leishmania major infection. PLoS Pathog. 9, e 1003243 (2013)

94. Bacellar, O. et al. Interleukin 17 production among patients with American cutaneous leishmaniasis. J. Infect. Dis. 200, 75-78 (2009).

95. Boaventura, V. S. et al. Human mucosal leishmaniasis: neutrophils infiltrate areas of tissue damage that express high levels of Th17-related cytokines. Eur. J. Immunol. 40, 2830-2836 (2010).

96. Brodskyn, C. I., Barral, A., Boaventura, V., Carvalho, E. $\&$ Barral-Netto, M. Parasite-driven in vitro human lymphocyte cytotoxicity against autologous infected macrophages from mucosal leishmaniasis. J. Immunol. 159, 4467-4473 (1997).

97. Faria, D. R. et al. Recruitment of CD8+ T cells expressing granzyme $\mathrm{A}$ is associated with lesion progression in human cutaneous leishmaniasis. Parasite Immunol. 31, 432-439 (2009).

98. Santos Cda, S. et al. $\mathrm{CD}^{+}$granzyme $\mathrm{B}^{+}$-mediated tissue injury versus $\mathrm{CD} 4^{+} \mathrm{IFN} \gamma^{+}$-mediated parasite killing in human cutaneous leishmaniasis. J. Invest Dermatol. 133, 1533-1540 (2013). This work describes the cytolytic role of CD8 $T$ cells in $L$. braziliensis-infected patients.

99. Cardoso, T. M. et al. Protective and pathological functions of $\mathrm{CD} 8{ }^{+} \mathrm{T}$ cells in Leishmania braziliensis infection. Infect. Immun. 83, 898-906 (2015).

100. Novais, F. O. et al. Genomic profiling of human Leishmania braziliensis lesions identifies transcriptional modules associated with cutaneous immunopathology. J. Invest. Dermatol. 135, 94-101 (2015).

101. Novais, F. O. et al. Cytotoxic T cells mediate pathology and metastasis in cutaneous leishmaniasis. PLoS Pathog. 9, e1003504 (2013).

This paper is the first to demonstrate that cytolytic CD8 ${ }^{+} \mathrm{T}$ cells kill infected cells in a perforin-dependent manner, leading to severe pathology.

102. Crosby, E. J., Goldschmidt, M. H., Wherry, E. J. \& Scott, P. Engagement of NKG2D on bystander memory
CD8 T cells promotes increased immunopathology following Leishmania major infection. PLoS Pathog. 10, e1003970 (2014)

103. Da-Cruz, A. M., Oliveira-Neto, M. P., Bertho, A. L., Mendes-Aguiar, C. O. \& Coutinho, S. G. T cells specific to Leishmania and other nonrelated microbial antigens can migrate to human leishmaniasis skin lesions. J. Invest. Dermatol. 130, 1329-1336 (2010).

104. Dotiwala, F. et al. Killer lymphocytes use granulysin, perforin and granzymes to kill intracellular parasites. Nat. Med. 22, 210-216 (2016).

105. Kostka, S. L., Knop, J., Konur, A., Udey, M. C. \& von Stebut, E. Distinct roles for IL-1 receptor type I signaling in early versus established Leishmania major infections. J. Invest. Dermatol. 126, 1582-1589 (2006).

106. Lima-Junior, D. S. et al. Inflammasome-derived IL-1 $\beta$ production induces nitric oxide-mediated resistance to Leishmania. Nat. Med. 19, 909-915 (2013).

This study indicates that inflammasome-dependent IL-1 $\beta$ helps control some Leishmania spp. infections via an NO-dependent pathway.

107. von Stebut, E. et al. Interleukin $1 \alpha$ promotes Th1 differentiation and inhibits disease progression in Leishmania major-susceptible BALB/c mice. J. Exp. Med. 198, 191-199 (2003).

108. Kautz-Neu, K. et al. A role for leukocyte-derived IL-1RA in DC homeostasis revealed by increased susceptibility of IL-1RA-deficient mice to cutaneous leishmaniasis. J. Invest. Dermatol. 131, 1650-1659 (2011).

109. Fernandez-Figueroa, E. A. et al. Disease severity in patients infected with Leishmania mexicana relates to IL-1 $\beta$. PLoS Negl. Trop. Dis. 6, e1533 (2012).

110. Ikejima, T., Okusawa, S., Ghezzi, P., van der Meer, J. W. \& Dinarello, C. A. Interleukin-1 induces tumor necrosis factor (TNF) in human peripheral blood mononuclear cells in vitro and a circulating TNF-like activity in rabbits. J. Infect. Dis. 162, 215-223 (1990).

111. Gurung, P. et al. An NLRP3 inflammasome-triggered Th2-biased adaptive immune response promotes leishmaniasis. J. Clin. Invest. 125, 1329-1338 (2015).

112. Bryson, K. J., Wei, X. O. \& Alexander, J. Interleukin-18 enhances a Th2 biased response and susceptibility to Leishmania mexicana in BALB/c mice. Microbes Infect. 10, 834-839 (2008)

113. Xu, D. et al. IL-18 induces the differentiation of Th 1 or Th2 cells depending upon cytokine milieu and genetic background. Eur. J. Immunol. 30, 3147-3156 (2000)

114. Shio, M. T., Christian, J. G., Jung, J. Y., Chang, K. P. \& Olivier, M. PKC/ROS-mediated NLRP3 inflammasome activation is attenuated by Leishmania zincmetalloprotease during Infection. PLoS Negl. Trop. Dis. 9, e0003868 (2015)

115. Lefevre, L. et al. The C-type lectin receptors dectin-1, $\mathrm{MR}$, and SIGNR3 contribute both positively and negatively to the macrophage response to Leishmania infantum. Immunity 38, 1038-1049 (2013).

116. Campanelli, A. P. et al. $\mathrm{CD} 4{ }^{+} \mathrm{CD} 25^{+} \mathrm{T}$ cells in skin lesions of patients with cutaneous leishmaniasis exhibit phenotypic and functional characteristics of natural regulatory T cells. J. Infect. Dis. 193 1313-1322 (2006)

117. Bourreau, E. et al. Intralesional regulatory T-cell suppressive function during human acute and chronic cutaneous leishmaniasis due to Leishmania guyanensis. Infect. Immun. 77, 1465-1474 (2009).

118. Rodriguez-Pinto, D. et al. Regulatory T cells in the pathogenesis and healing of chronic human dermal leishmaniasis caused by Leishmania (Viannia) species. PLoS Negl. Trop. Dis. 6, e1627 (2012)

119. Suffia, I. J., Reckling, S. K., Piccirillo, C. A., Goldszmid, R. S. \& Belkaid, Y. Infected site-restricted Foxp3 ${ }^{+}$natural regulatory $T$ cells are specific for microbial antigens. J. Exp. Med. 203, 777-788 (2006).

120. Yurchenko, E. et al. CCR5-dependent homing of naturally occurring $\mathrm{CD}^{+}{ }^{+}$regulatory $\mathrm{T}$ cells to sites of Leishmania major infection favors pathogen persistence. J. Exp. Med. 203, 2451-2460 (2006)

121. Okwor, I., Liu, D., Beverley, S. M. \& Uzonna, J. E. Inoculation of killed Leishmania major into immune mice rapidly disrupts immunity to a secondary challenge via IL-10-mediated process. Proc. Natl Acad. Sci. USA 106, 13951-13956 (2009).

122. Mendez, S., Reckling, S. K., Piccirillo, C. A., Sacks, D. $\&$ Belkaid, Y. Role for $\mathrm{CD}^{+}{ }^{+} \mathrm{CD} 25^{+}$regulatory T cells in reactivation of persistent leishmaniasis and control of concomitant immunity. J. Exp. Med. 200, 201-210 (2004). 
123. Ji, J., Masterson, J., Sun, J. \& Soong, L. CD4+CD25+ regulatory $T$ cells restrain pathogenic responses during Leishmania amazonensis infection. J. Immunol. 174, 7147-7153 (2005)

124. Ehrlich, A. et al. The immunotherapeutic role of regulatory T cells in Leishmania (Viannia) panamensis infection. J. Immunol. 193, 2961-2970 (2014).

125. Costa, D. L. et al. Tr-1-like CD4+ CD 25-CD 127-flow FOXP3- cells are the main source of interleukin 10 in patients with cutaneous leishmaniasis due to Leishmania braziliensis. J. Infect. Dis. 211, 708-718 (2015).

126. Salhi, A. et al. Immunological and genetic evidence for a crucial role of IL-10 in cutaneous lesions in humans infected with Leishmania braziliensis. J. Immunol. 180, 6139-6148 (2008).

127. Naik, S. et al. Compartmentalized control of skin immunity by resident commensals. Science 337 , 1115-1119 (2012).

This study is the first to show that skin commensals can exacerbate pathology in cutaneous leishmaniasis.

128. Peters, N. C. et al. Vector transmission of leishmania abrogates vaccine-induced protective immunity. PLoS Pathog. 5, e1000484 (2009).

129. Chang, J. T., Wherry, E. J. \& Goldrath, A. W. Molecular regulation of effector and memory $T$ cell differentiation. Nat. Immunol. 15, 1104-1115 (2014).

130. Khamesipour, A et al. Leishmanization: use of an old method for evaluation of candidate vaccines against leishmaniasis. Vaccine 23, 3642-3648 (2005).

131. The Working Group on Research Priorities for Development of Leishmaniasis Vaccines et al.
Vaccines for the leishmaniases: proposals for a research agenda. PLoS Negl. Trop. Dis. 5, e943 (2011).

132. Noazin, S. et al. First generation leishmaniasis vaccines: a review of field efficacy trials. Vaccine $\mathbf{2 6}$ 6759-6767 (2008)

133. Coffman, R. L., Sher, A. \& Seder, R. A. Vaccine adjuvants: putting innate immunity to work. Immunity 33, 492-503 (2010).

134. Reed, S. G., Orr, M. T. \& Fox, C. B. Key roles of adjuvants in modern vaccines. Nat. Med. 19 , 1597-1608 (2013)

135. Mou, Z. et al. Identification of broadly conserved cross-species protective Leishmania antigen and its responding CD4+ T cells. Sci. Transl. Med. 7. 310 ra167 (2015)

This study identifies an immunodominant antigen that provides long-lasting protection to several Leishmania spp.

136. Reed, S. G., Coler, R. N., Mondal, D., Kamhawi, S. \& Valenzuela, J. G. Leishmania vaccine development exploiting the host-vector-parasite interface. Expert Rev. Vaccines 15, 81-90 (2016).

137. Oliveira, F. et al. A sand fly salivary protein vaccine shows efficacy against vector-transmitted cutaneous leishmaniasis in nonhuman primates. Sci. Transl. Med. 7, 290 ra90 (2015).

138. Anderson, C. F., Mendez, S. \& Sacks, D. L. Nonhealing infection despite Th1 polarization produced by a strain of Leishmania major in C57BL/6 mice. J. Immunol. 174, 2934-2941 (2005).

139. McMahon-Pratt, D. \& Alexander, J. Does the Leishmania major paradigm of pathogenesis and protection hold for New World cutaneous leishmaniases or the visceral disease? Immunol. Rev. 201, 206-224 (2004)

140. Ji, J., Sun, J., Qi, H. \& Soong, L. Analysis of T helper cell responses during infection with Leishmania amazonensis. Am. J. Trop. Med. Hyg. 66, 338-345 (2002).

141. Qi, H., Popov, V. \& Soong, L. Leishmania amazonensis-dendritic cell interactions in vitro and the priming of parasite-specific $\mathrm{CD}^{+} \mathrm{T}$ cells in vivo. J. Immunol. 167, 4534-4542 (2001).

142. Satoskar, A., Bluethmann, H. \& Alexander, J. Disruption of the murine interleukin-4 gene inhibits disease progression during Leishmania mexicana infection but does not increase control of Leishmania donovani infection. Infect. Immun. 63, 4894-4899 (1995).

143. Stamm, L. M. et al. Mice with STAT6-targeted gene disruption develop a Th1 response and control cutaneous leishmaniasis. J. Immunol. 161 6180-6188 (1998)

Acknowledgements

The authors thank L. King for critical reading of the manuscript and acknowledge financial support from the US National Institutes of Health (RO1 Al 106842; UO1 Al 088650; RO1 Al 125126).

Competing interests statement

The authors declare no competing interests.

SUPPLEMENTARY INFORMATION

See online article: $\underline{\mathrm{S} 1}$ (movie)

ALL LINKS ARE ACTIVE IN THE ONLINE PDF 